\title{
BALANCING THE TRIPLE BOTTOM LINE: BUILDING A CREDIBLE AND FUNDABLE SMART GRID BUSINESS CASE
}

\author{
ROBERT J. SARFI ${ }^{1}, \mathrm{KEN} \mathrm{LEE}^{2}$ \& LEOPOLDO A. GEMOETS ${ }^{3}$ \\ ${ }^{1}$ Boreas Group LLC, USA \\ ${ }^{2}$ New York Power Authority, USA \\ ${ }^{3}$ University of Texas El Paso, USA
}

\begin{abstract}
For many electric utilities North America, justifying Smart Grid and combined Smart Grid or Smart City initiatives have become particularly challenging. For the most part, while the benefits of the technologies have been proven, prior generations of technology have already claimed benefit, regulators are weary, and federal subsidies are waning. As a consequence, developing a business case for technology implementation, upgrade, or enhancement presents a veritable challenge. The reality of todays context is that: Technology is expensive; Next to wholesale energy costs, payroll is the second highest cost for a utility; Hard dollar benefits are elusive because most utilities are concerned about impending staff retirements, the acquisition of new talent is challenging and expensive, and they are understaffed in many areas; On-going costs are often underestimated in order to justify projects. Given this context, public power entities and municipal governments struggle to develop a compelling business case to move forward with implementing the fundamental architectural components of a Smart Grid or Smart City. The current model used by utilities to justify large technology investment is dated, and simply no longer relevant. This is the first part of a two-part paper that discusses how utilities can use the concept of the Triple Bottom Line (TBL) to justify investment that is measured in terms of Economic, Societal, and Environmental benefit. While TBL is well understood in many developing nations it is relatively unheard of by North America utilities. This first paper will discuss how to define, quantify, appreciate, and harvest value from technology investment. A subsequent paper will follow the utilities identified in this paper as they measure the TBL benefits of their technology investments. Keywords: smart grid, smart city, Triple Bottom Line, TBL.
\end{abstract}

\section{INTRODUCTION}

In the late 1990's industry pundits defined the moniker "Smart Grid" to describe an approach to modernize electrical distribution that would transform the way that a utility interacted with its customers in order to provide a higher level of service and reliability, put the customer in control of their energy costs, and to achieve energy conservation and sustainability goals. Loosely defined, the Smart Grid included increased automation from the premise to the utility infrastructure, increased use of distributed renewable generation, a high adoption rate of plug-in electric vehicles that could be used to support the need for energy during critical times, and self-healing mechanisms. While slow to be embraced by the industry, at the height of the US stock market rally of 2007, it appeared as though the industry as a whole would be required invest in the infrastructure to embark on these changes with dispatch. Coupled with efforts to reduce the impact of "Global Warming" the interest in the Smart Grid was not limited to North America or Western Europe, many Asian and Middle Eastern utilities also embarked on the Smart Grid journey.

While the new United States Presidential Administration has taken active steps to rollback legislation and funding that promoted renewables, sustainability, and any activity designed to counter climate change, utilities are cognizant that they need to continue to take steps to change the manner in which they generate, distribute, and consume energy. In summary, in 
the absence of any stimulus from the federal level, the pressure to deliver and use energy in a more sustainable manner remains at the forefront of society's concerns. As such, many municipal and community owned utility systems face new challenges to embark on ambitious modernization programs that only a year ago appeared to be inevitable. Municipalities that are not preparing and staging for this transformation will find themselves in an increasingly unfavourable position that may challenge the very nature of their public ownership.

To further complicate the situation for small to mid-tier utilities, e.g. less than 300,000 meters, there are associated economy of scale issues that they must overcome. For the large investor owned and municipal utilities, i.e. those with greater than 1 million meters, the cost of implementing more efficient technology is more easily absorbed through the economy of scale. In many cases, these larger utilities have positioned themselves as industry leaders, setting the example for the industry as a whole, e.g. Xcel Energy's Smart Grid City. While the smaller and mid-tier utilities have societal and potentially regulatory obligations to achieve the same conservation and sustainability goals as their larger breather, they do not have a sufficient customer base to overcome the high cost of entry. To add to the normal risks associated with large system integration projects and the increased interaction with the citizen, many of the technology components of the Smart Grid remain very immature.

For those who have fiscal responsibility for the performance of the utility the Smart Grid presents a daunting challenge. At the present time, price point for infrastructure remains very high and the cost of energy to the consumer too low to justify the seemingly unconscionable investment. Unfortunately, due to the relatively small number utilities that have embarked on Smart Grid initiatives to date, there is little more than anecdotal records to help other municipal and community distribution companies in building a successful Smart Grid Roadmap. This paper builds a framework to trace several utilities that were previously analysed by the authors [1]. Previously, the utilities assessed in [1] embarked on "smarter grid" initiatives that strived to deliver Smart Grid benefits, without investing in the based technology elements of architectural components of the Smart Grid. The approach presents a pragmatic and systematic way of developing a cost benefit analysis that considers qualitative benefits in addition to the elusive hard dollar benefits in order to make a compelling business case.

The authors have identified a framework to analyse the potential TBL benefits from the perspective of the TBL and will follow them from justification through implementation through realization or harvesting of benefits, we call this the TBL-based balanced scorecard. The lessons learned from these utilities can be used by a municipal or community owned electrical distribution system to develop a roadmap to a Smart Grid or Smart City. A roadmap prepared using the principals identified in this paper will allow the municipality to demonstrate forward momentum to achieve energy conservation and sustainability goals, while recognizing and acknowledging the need for fiscal restraint and judicious risk management, as well as measurement and attainment of societal and environmental objectives. These utilities all have one common understanding about Smart Grid: they have prepared a three to five year roadmap in detail that realizes many goals of the Smart Grid without committing to the full Smart Grid envisioned by the vendor community and many elected representatives.

This paper includes six sections:

1. Introduction - an overview of the paper as a whole

2. Triple Bottom Line - a brief definition of the TBL and contrast to conventional electric utility project justification approaches

3. The Vision - the target that utilities in North America are trying to realize 
4. Participant Utilities - a description of utilities that we will follow

5. Approach - our proposed approach

6. Conclusion - concluding remarks.

\section{TRIPLE BOTTOM LINE}

In order to understand why the TBL is such a powerful approach for utilities, it is important to understand the shortcomings of the current investment model. This section will present the existing utility investment approach, and discuss how TBL can be applied. A discussion of what fundamentally needs to change in the overall utility context to promote more progressive investment is also presented. This will allow us to understand how the Vision presented in the next section can be better justified.

\subsection{Existing investment approach}

In the recent past, North American utilities have justified large capital investments in technology, such as those required of a Smart Grid, solely based on hard dollar business cases. This approach is reinforced in the Electric Power "Research Institute's Guidebook for Cost/Benefit Analysis for Smart Grid Demonstration Projects: Part 1 Measuring Impacts (CBA Guidebook)" [2]. The "CBA Guidebook" provides a comprehensive framework that provides a comprehensive list of potential benefits and a means of calculating the perceived net present value of the investment in terms of the Total Cost of Ownership (TCO). Very loosely, the benefits are typically categorized as follows:

- Demand side management/energy efficiency, e.g. inherently more efficient technology or an enabler for a behaviour change

- Customer empowerment, e.g. technology that enables a customer behaviour change.

- Grid optimization and management, e.g. reduction of technical and non-technical losses, improved reliability, etc.

- Hardening of critical infrastructure, e.g. ensuring energy delivery

- New revenue opportunity, e.g. lease of RF bandwidth for other services such as street light control, pollution sensors, or a new customer product or service, etc.

While the "CBA Guidebook" framework remains a capable tool for calculating hard benefits, utilities recent experience is that the recommended approach is only part of the justification. Simply stated North American utilities are discovering that a business case based solely on hard benefits is no longer sufficient to justify large technology expenditures. The traditional approach is failing due to the following:

- Utilities have already claimed benefit for individual technology investment, e.g. process outsourced or paging-based demand response

- A hesitation to consider any benefits that require a customer behaviour change, e.g. time of use rates are ineffective because typical $\mathrm{kWh}$ charges are very low

- A regulatory framework that doesn't actually reward grid efficiencies, e.g. losses are rolled into the rate for a guaranteed return, so long as losses are deemed acceptable by regulator, or allow recovery for SaaS or cloud offerings

- Reluctance to broach "smart" rates with a regulatory, e.g. performance based rates are frowned upon because of the associated uncertainty

- Complicated processes for new, unregulated products and services, e.g. no one wants to change 
- Dated accounting rules that dictate investments are depreciated over a 15 to 20 year period: widely acknowledged as beyond the life-expectancy of the investments

- Low commodity price outlook due to low cost shale gas, e.g. very low commodity price over investment horizon does not motivate efficiencies or renewables.

- Lack of transparency, e.g. utilities are hesitant by culture to publish performance measures in a repeatable and traceable manner.

It is important to note that the retail cost of electricity in the United States is particularly low: in 2016, the average residential rate was $\$ 0.1028 / \mathrm{kWh}$. This is in contrast to approximately $\$ 0.22 / \mathrm{kWh}$ in the European Union (EU-28) and can go to approximately $\$ 0.41 / \mathrm{kWh}$. In addition, regulation related to emissions and renewable targets are not as stringent overall in North America as they are in Europe. As a consequence, the North American approach to Smart Grids and Smart Cities is very different, and more difficult to gain support for and justify.

\subsection{Why the TBL}

Faced with the problem of justifying new investment in face of the obstacles presented in Section 2.1, North American utilities can turn to the TBL approach. The TBL was first presented in 1994 by Elkington [3]. The TBL provides a means of measuring not only the financial performance of an investment but, as well, considers environmental and societal objectives. TBL can also be referred to as 3P investing: Profit, Planet, People. A preliminary application of the TBL to utilities is also described in [4]. While some Canadian provincial utilities discuss the importance of societal and environmental impact there has been little effort to monetize these.

Utilities have traditionally avoided some of the typical TBL benefits because non-hard or quantitative benefits are often viewed as dubious. In addition, deferred costs and employee productivity (not including a reduction in force, reduction of overtime, or natural attrition) are also typically viewed with scepticism. This is largely due to the utility industry's hesitate to publish any data or performance based results beyond what is required by regulatory bodies.

In developing nations, the TBL has become an effective tool to demonstrate that the impact of investment goes will beyond financial returns. In the case of investor owned utilities, publicly owned utilities, such as municipal utilities, and member owned cooperatives the is a general recognition that meeting environmental and societal goals should be of importance, but it has not been assigned any value in business cases that are based solely on a NPV of investments.

The authors have observed that where a utility has demonstrated clear social or environmental benefit to stakeholder groups, as well as a willingness to measure and publish performance to plan, there is little resistance on the part of the regulatory body or stakeholders to provide project funding. In essence, the TBL can be used to capture what stakeholders value in order to justify further investment from them. While quite a simple concept, it has not been used as an industry wide strategy that views stakeholders and regulators as true partners. This model also promotes public-private partnership models. As a consequence of this observation, the authors have identified and recruited a series of utilities to employ a TBL-based strategy to justify investment. 


\subsection{Needed changes}

In order to realize the TBL-based strategies, there is a need to change certain parameters of the utilities ecosystem in North America. Utilities, their stakeholders, and regulators need to embrace the following:

- Regulatory change in recovery mechanisms for both capital investment, as well as O\&M, which is not the case today

- Regulatory change, in consumer rates and to allow for new products and services, as well as, a means of segregating revenue and investment in assets that overlap in regulated and non-regulated usage

- Transparency in performance measurement, in open and repeatable measurement of the programs

- Appreciation for a holistic view of change, specifically to encourage investment in a platform as opposed to a point technology solution

- A willingness to embrace cultural change within the utility.

Sadly, at this time, not all of these elements are in place. For any Smart Grid program to be successful, it is necessary for the utility and its stakeholders to embrace the five pillars of change identified below in Fig. 1 is an extension of the popular Leavitt's Diamond of Change, with the addition of culture and governance. For many utilities, the cost of true process, cultural, and governance change has not been a priority and as a consequence lacklustre results have been witnessed in technology investments. Based on an understanding of the issues with the current investment approach used by North American utilities, a discussion of the Smart Grid and its components will be presented.

It is important to note that the aspirational model for utilizes relies on a tightly integrated system enabled by data exchange across the ubiquitous communications infrastructure. Many utilities struggle with this as they can only justify capacity for their internal use, and not for third party opportunities. For example, an electric-only utility would struggle to share network capacity with a water utility. This duplication of resources needs to be addressed, and is captured using the TBL approach. The next section presents an approach how the TBL will be used to assist utilities performed a more robust project justification.

\section{THE VISION}

Despite our dependence on electric power, as a society we have done little to modernize energy delivery until relatively recently. Sadly, the advances have not kept up with the values of our society as a whole, or proven, commonly available technology. Whereas in the past
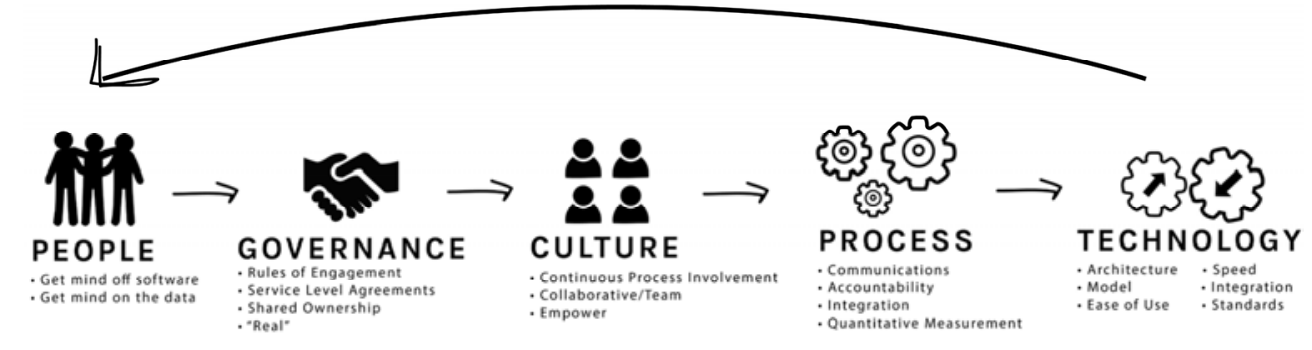

Figure 1: Pillars of success. 
change was driven by regulated entities with an exclusive franchise, disruptors will come from outside of the power sector: this is a phenomenon we are already witnessing, with increasing velocity. The grid of the future will provide an open platform, much similar to a state-owned interstate that allows access to all. Generation, storage, and load elements will be self-registering building blocks, similar to the concept of all "Lego" sets being compatible. Elements will be connected by providers or even consumers, they will self-register, and interact with each other optimizing grid performance with respect to economics, efficiency, adequacy, and reliability. The ubiquitous grid will encompass not only electric, gas, and water, but as well other services that we've already come to rely upon or haven't even considered yet. How real is this vision? Consider that most of these components are commonly available or the concepts are in use in other sectors and applications. This is very real and likely within all of our lifetimes. Is this farewell to the grid as we know it? A pragmatist may say we are in a transitional state where not acknowledging and recognizing change will lead to certain obsolescence.

For many, the Smart Grid is the rallying point for enabling sustainability in the electric utility. Sustainability is a term that takes many interpretations. From an electric utility perspective, sustainability encompasses energy independence, the environment, and efficiency. While consumers and special interest groups often measure sustainability from the sole perspective of energy delivery and end-point consumption, responsible utilities perpetuate these values in the manner in which the conduct their business internally. Sustainability consequently satisfies a need to demonstrate both corporate social responsibility (CSR), as well as, provides a means of either controlling costs or providing consumers with a means of rationalizing increased rates.

At the present time, most utilities have relatively low-cost rates. Short of abstaining from the use of devices and equipment that consumes electrical energy, sustainability is enabled through changes in consumer behaviour, typically enabled through new technology. The cost of sustainability is consequently very high. Quite often this paradigm shift is bundled under the overall umbrella of a Smart Grid initiative.

Fig. 2 presents a high-level perspective of the Smart Grid [6]. A critical component of Fig. 1 is the now commonly accepted view of the customer empowerment that places the onus on the customer to make energy related decisions as opposed to the utility: for many utilities, this will be the most challenging aspect of the Smart Grid to respond to as residential customer behaviour will not be consistently predictable. This vision of Fig. 1 represents the typical target or destination for most utility technology plans. While many Smart Grid consortiums, such as IntelliGrid or GridWise, now provide a more detailed definition of the components of the Smart Grid, there remains considerable ambiguity. In fact, the Department of Energy ARRA funding for Smart Grid Demonstration projects was delayed due to concerns over a lack of standards for communications and cybersecurity. A significant challenge for many smaller entities is in fact developing and implementing a credible cybersecurity plan. 

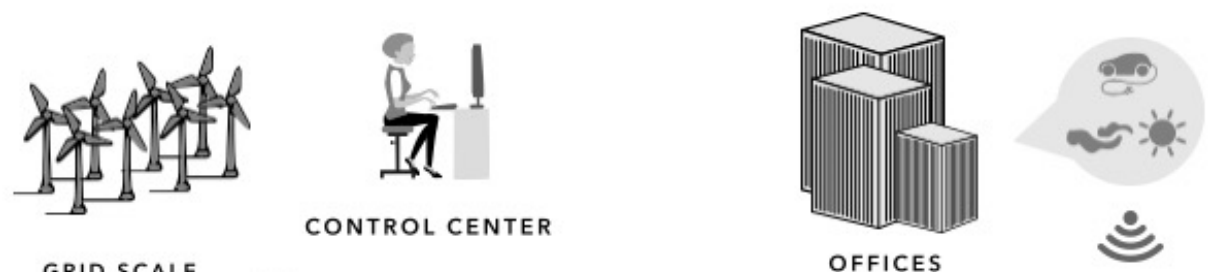

GRID SCALE RENEWABLES
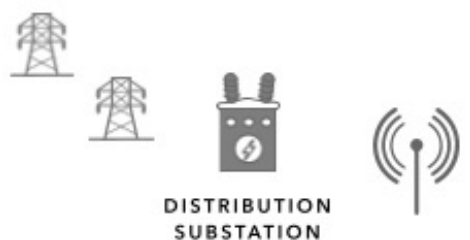

OFFICES
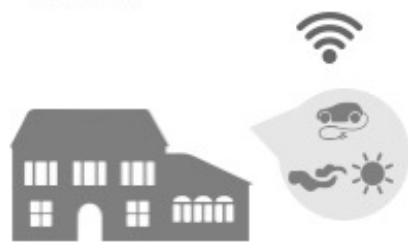

RESIDENTIAL
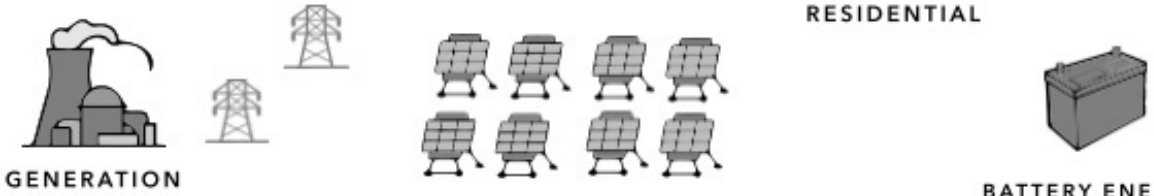

COMMUNITY ENERGY

BATTERY ENERGY STORAGE

Figure 2: Commonly accepted Smart Grid vision.

Within Fig. 2, it is important to note that:

- The underlying foundation of any Smart Grid or Smart City initiative is a ubiquitous communications infrastructure that allows peer-peer decentralized and centralized control, as well as, enables edge computing.

- Smart Grid initiatives are often built on the foundation established by the geospatially enabled asset management trends as initiated at the onset of the millennium.

- The increased presence of advanced metering infrastructure or smart meter initiative (AMI / SMI) either currently deployed or in advanced pilot programs at most major North American utilities are viewed as the first step in creating a smart grid initiative.

- More advanced Smart Grid initiatives are also striving to include extensive automation downstream of the distribution substation, decentralized renewable generation, and early stage storage technologies to enable a both self-healing infrastructure and a zero emissions environment.

Seven system components are now accepted by electric utilities to be the Fundamental Technology Layer that is central to most modern utilities and required prior to the implementation of many advanced technologies. These seven Fundamental Technology Layer components are: Customer Information System (CIS)

- Geographic Information System (GIS) and graphical design

- Work Management System (WMS)

- Computerized Maintenance Management System (CMMS)

- Advanced Distribution Management System (ADMS)

- Advanced Metering Infrastructures (AMI), including meter data management (MDM)

- Distribution Automation (DA)/SCADA. 


\section{PARTICIPANT UTILITIES}

By nature, North American utilities are very guarded about project justification and performance validation, other than data required in regulatory filings. Even in the case of public utilities that are subject to Freedom of Information Act (FOIA) disclosures financial information is often protected. The consequence of this is that it becomes very difficult, and very time, if not impractical to collect empirical data related to project justification and validation. In many cases there is in fact an "artistic license" associated with reported data.

Table 1: Case study overview.

\begin{tabular}{|c|c|c|c|c|}
\hline Case & $\begin{array}{l}\text { Description (Location, } \\
\text { Demographics) }\end{array}$ & $\begin{array}{l}\text { Initial State } \\
\text { Baseline State, } \\
\text { Pre [1] }\end{array}$ & $\begin{array}{l}\text { State } \\
\text { justified and } \\
\text { realized in } \\
\text { [1] }\end{array}$ & $\begin{array}{l}\text { State to be } \\
\text { justified with } \\
\text { TBL } \\
\text { methodology }\end{array}$ \\
\hline 1 & $\begin{array}{l}\text { Heartland, Rural with } \\
\text { Agribusiness / Agricultural, } \\
\text { High Rural Poverty }(3,000 \\
\text { meters) }\end{array}$ & $\begin{array}{l}\text { AMR and no } \\
\text { Automation }\end{array}$ & AMI and DR & $\begin{array}{l}\text { Multi-use } \\
\text { Communication, } \\
\text { Advanced Apps }\end{array}$ \\
\hline 2 & $\begin{array}{l}\text { West, Primary Industries, High } \\
\text { Rural Poverty ( } 3,000 \text { meters) }\end{array}$ & $\begin{array}{l}\text { Manual Meter Reads } \\
\text { and SCADA }\end{array}$ & $\begin{array}{l}\text { In Home } \\
\text { Control and } \\
\text { Line DA }\end{array}$ & $\begin{array}{l}\text { Multi-use } \\
\text { Communication, } \\
\text { Advanced Apps }\end{array}$ \\
\hline 3 & $\begin{array}{l}\text { Heartland, Rural with } \\
\text { Agricultural, Economically } \\
\text { Depressed (5,000 meters) }\end{array}$ & AMR and SCADA & $\begin{array}{l}\text { AMI and } \\
\text { Line DA }\end{array}$ & $\begin{array}{l}\text { Multi-use } \\
\text { Communication, } \\
\text { Advanced Apps }\end{array}$ \\
\hline 4 & $\begin{array}{l}\text { Southwest, Rural and Suburban } \\
\text { with Agricultural and Light } \\
\text { Commercial ( } 80,000 \text { meters) }\end{array}$ & $\begin{array}{l}\text { Manual Meter Reads } \\
\text { and Extensive Station } \\
\text { DA }\end{array}$ & $\begin{array}{l}\text { AMI and } \\
\text { Line DA }\end{array}$ & $\begin{array}{l}\text { Multi-use } \\
\text { Communication, } \\
\text { Advanced Apps, } \\
\text { DER }\end{array}$ \\
\hline 5 & $\begin{array}{l}\text { Pacific North West, Suburban, } \\
\text { Affluent and Environmentally } \\
\text { Friendly ( } 80,000 \text { meters) }\end{array}$ & $\begin{array}{l}\text { AMR and Extensive } \\
\text { Station DA }\end{array}$ & $\begin{array}{l}\text { AMI and } \\
\text { Line DA }\end{array}$ & $\begin{array}{l}\text { Multi-use } \\
\text { Communication, } \\
\text { Advanced Apps, } \\
\text { DER }\end{array}$ \\
\hline 6 & $\begin{array}{l}\text { Mid-Atlantic, Rural with } \\
\text { Agricultural and Light } \\
\text { Manufacturing ( } 80,000 \text { meters) }\end{array}$ & $\begin{array}{l}\text { AMR and Extensive } \\
\text { Station DA }\end{array}$ & $\begin{array}{l}\text { AMI and } \\
\text { Line DA }\end{array}$ & $\begin{array}{l}\text { Multi-use } \\
\text { Communication, } \\
\text { Advanced Apps, } \\
\text { DER }\end{array}$ \\
\hline 7 & $\begin{array}{l}\text { Heartland, Dense Suburban, } \\
\text { Very Affluent ( } 80,000 \text { meters) }\end{array}$ & $\begin{array}{l}\text { AMR and Extensive } \\
\text { Station DA }\end{array}$ & $\begin{array}{l}\text { In Home } \\
\text { Controllers }\end{array}$ & $\begin{array}{l}\text { Multi-use } \\
\text { Communication, } \\
\text { Advanced Apps, } \\
\text { DER }\end{array}$ \\
\hline 8 & $\begin{array}{l}\text { West, Suburban with Light } \\
\text { Manufacturing and } \\
\text { Commercial, Economically } \\
\text { Depressed ( } 80,000 \text { meters) }\end{array}$ & $\begin{array}{l}\text { Manual Meter Reads } \\
\text { and Moderate Station } \\
\text { DA }\end{array}$ & $\begin{array}{l}\text { AMI and } \\
\text { Renewables } \\
\text { Integration }\end{array}$ & $\begin{array}{l}\text { Multi-use } \\
\text { Communication, } \\
\text { Advanced Apps, } \\
\text { DER }\end{array}$ \\
\hline
\end{tabular}


As a consequence, the proposed approach is to build a model for project justification using TBL, then to apply the model to select utilities in order to gauge its effectiveness. As a consequence, the same utilities that participated in the study identified in [1], which put in place a "Smarter Grid" were solicited to participated in this effort.

Table 1 provides a list of the utilities demographics, a summary of the extent of their automation, and chronicles the progression from a traditional utilities with a single commodity to a "Smarter Grid" as described in [1], to a modern utility that has invested in a platform to support multi-commodity, multi-use Smart Grid or City initiatives including a multi-tiered control strategy and edge computing.

Table 1 provides a high-level synopsis of the characteristics of the eight utilities that will apply the TBL model to justify further modernization of their grid. While the eight utilities of Table 1 are very diverse in terms of size, service territory, and load diversity, there are numerous similarities that must be noted:

- With two exceptions, these utilities serve a population that is neither affluent or progressive with respect to preservation of the environment

- With one exception, these utilities face financial pressures

- All embarked proactively on their Smart Grid initiatives in anticipated of impending changes in the way that they are expected to conduct themselves

- Following a successful implementation as described in [1] they will embark on the TBLbased justification model

- All are striving to implement a multi-use, hybrid, ubiquitous commination infrastructure based on unlicensed mesh-network RF and fibre

- None received rate relief to embark on their Smart Grid initiative, e.g. there are no rate increases directly attributable to the investment

- All have embarked on their initiatives with the goal of meeting the needs of their constituents and have not actively self-promoted beyond their own community.

Within Table 1, the following should be noted:

- The multi-use communications infrastructure is considered the cost of entry to supporting Smart Grid and Smart City initiatives. Its justification is often complicated by the ability to immediately deliver benefits using point technology solutions.

- DER represents Distributed Energy Resources at the premise, community, and grid level which we define to include both, e.g. PV, wind, etc., and storage.

- Advanced applications are those enabled by centralized and decentralized control schemes, e.g. Volt-VAR optimization, conservation voltage reduction, revenue protection or theft identification, phase identification, etc.

\section{APPROACH}

In Section 2, we have identified a need to go beyond the traditional hard dollar cost justifications for utility capital projects. We also presented the opportunity to use the TBL approach in an electric utility setting in that section. With a lack of readily available quantitative data to prove out model, we recruited several utilities to participate in validation of the approach, this is presented in Section 4. This section will describe our model for cost justification of Smart Grid and Smart City initiatives.

Fig. 3 presents a flow diagram that describes how we will apply the model to the utilities identified as participants. Within Fig. 3 the most challenging component that will lend itself 


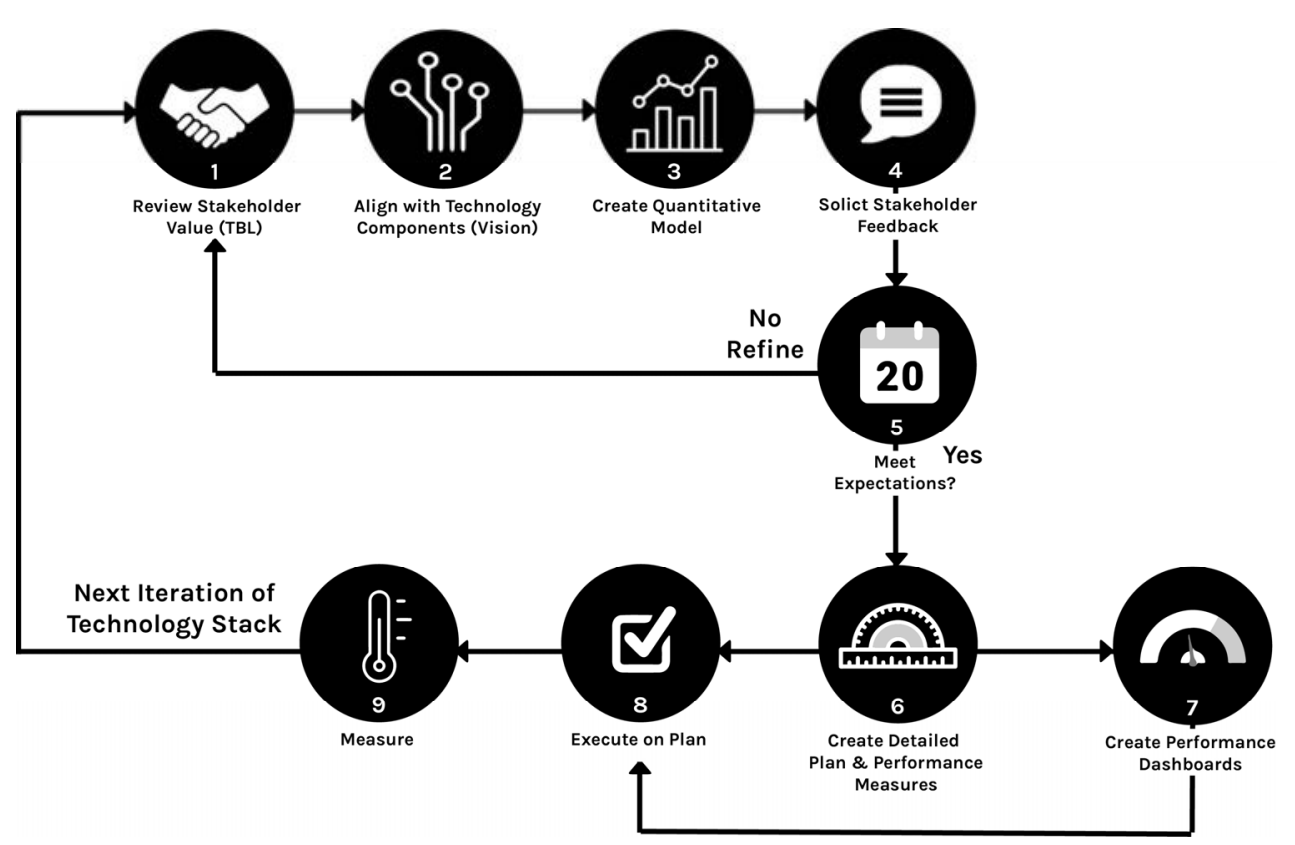

Figure 3: Approach.

to some level of scepticism is in the quantitative measurement of intangible goals of the TBL. In order to develop a grounded model, we use the OECD guidelines for TBL measurement, as defined in [7]. We will also use the OECD guidelines for measurement and assessment of innovation within this model [8]. Quantifying and placing value on criteria that is inherently qualitative by nature is always difficult. Using the established and accepted OECD guidelines takes the "Art" out of the approach. The integration of TBL and the OECD measurement guidelines for the TBL and innovation is itself novel within the North American utility context and represents a heightened recognition of the value of sustainability.

Table 2 presents a detailed task description of the activities involved in the operationalization of the model within the utility context. A novel critical success factor of the model is the two feedback loops to alter the recommended cost justification, based on evaluation of the stakeholders' value. This is performed prior to the technology vision going to the planning stage, allowing the utility to ensure that the solution to be deployed meets stakeholder's expectations. As well, the technology is typically deployed in phases: between each phase there is validation of its perceived stakeholder value, allowing for refinement.

\section{CONCLUSION}

Even though the final state of the Smart Grid is unknown, it has become a necessity for utilities to demonstrate forward momentum in the area of energy conservation and sustainability. This paper focuses on a methodology that will allow eight utilities to justify putting in place the base technology layers of the Smart Grid. Previously, utilities have avoided many base components and focused on point solutions to issues.

This paper has proposed using the TBL in order to justify the infrastructure projects associated with building out a Smart Grid or Smart City. At the present time, funding mechanisms are simply not functioning, and projects are not moving forward to meet 
Table 2: Task descriptions.

\begin{tabular}{|c|c|}
\hline Name & Description \\
\hline $\begin{array}{l}\text { Review } \\
\text { Stakeholder } \\
\text { Values }\end{array}$ & $\begin{array}{l}\text { Based on TBL categorization (Profit, People, Planet) Draw out a list of } \\
\text { benefit areas valued by all stakeholders and assign a prioritization. }\end{array}$ \\
\hline $\begin{array}{l}\text { With } \\
\text { Technology } \\
\text { Components } \\
\text { (Vision) }\end{array}$ & $\begin{array}{l}\text { Review benefit areas and develop a map to universe of Smart Grid and } \\
\text { Smart City technologies. Identify base architectural technology } \\
\text { components necessary to include in cost model. Plan out waves or } \\
\text { phases of technology deployments and associated stakeholder value. }\end{array}$ \\
\hline $\begin{array}{l}\text { Create } \\
\text { Quantitative } \\
\text { Model }\end{array}$ & $\begin{array}{l}\text { Use OECD methodology from }[7,8] \text { to develop quantitative benefit } \\
\text { realization model. Develop process change plan to harvest benefits. }\end{array}$ \\
\hline $\begin{array}{l}\text { Solicit } \\
\text { Stakeholder } \\
\text { Feedback }\end{array}$ & $\begin{array}{l}\text { Conduct stakeholder focus groups, as well as, social media based } \\
\text { education campaign and polls. }\end{array}$ \\
\hline $\begin{array}{l}\text { Meet } \\
\text { Expectations? }\end{array}$ & $\begin{array}{l}\text { Iterate on technology vision and value of benefits until meets } \\
\text { stakeholder expectations. Stakeholders need clear understanding of } \\
\text { outcomes and costs. }\end{array}$ \\
\hline $\begin{array}{l}\text { Create Detailed } \\
\text { Plan and } \\
\text { Performance } \\
\text { Measurement }\end{array}$ & $\begin{array}{l}\text { Based on final vision, a detailed plan will be developed to deploy the } \\
\text { technology in phases, and as well, to measure performance. }\end{array}$ \\
\hline $\begin{array}{l}\text { Create } \\
\text { Performance } \\
\text { Dashboards }\end{array}$ & $\begin{array}{l}\text { Based on Table } 3 \text {, create a set of dashboards, including forward-looking } \\
\text { analytics to capture the historical and forecasted performance of the } \\
\text { plan. In the past utilities may have not been entirely transparent, this } \\
\text { stage is important to gain stakeholder trust. }\end{array}$ \\
\hline $\begin{array}{l}\text { Execute on } \\
\text { Plan }\end{array}$ & Build out and operations of the technologies identified in the plan. \\
\hline Measure & $\begin{array}{l}\text { Validation of the performance of the plan to forecasts. It is essential that } \\
\text { this is published transparently to all stakeholders. Three levels of } \\
\text { performance are acceptable: 1) Meet plan, continue to next phase 2) } \\
\text { Sub-optimal performance, enact a corrective action plan 3) Complete } \\
\text { failure, rethink strategy as a whole. }\end{array}$ \\
\hline
\end{tabular}

stakeholder values and needs. The North American context is very different from Europe because of the relatively low cost of energy that makes justification of any sustainability initiative through hard savings very difficult. Bringing together the TBL in a North American utility is novel and will rely on proven quantitative methods documented by the OECD [7], [8].

Steps 1 and 2 of Fig. 3 have been completed, and work is underway to refine the quantitative model, Step 3. It is anticipated that the dashboard and associated analytics 
identified in Table 3 will be build out in parallel to the model development. Initial feedback from stakeholders have identified a support for the willingness of the utility to change.

Table 3: Analytics dashboards to measure and communicate program success.

\begin{tabular}{|l|l|}
\hline Use Case & Benefits \\
\hline Safety & $\begin{array}{l}\bullet \text { New technology will bring new safety challenges that need to be } \\
\text { anticipated }\end{array}$ \\
\hline $\begin{array}{l}\text { Triple Bottom } \\
\text { Line }\end{array}$ & $\begin{array}{l}\bullet \text { Societal, environmental, and financial pillars that are measured } \\
\text { Encapsulation of strategic plan in customer value }\end{array}$ \\
\hline Risk & $\begin{array}{l}\text {-Analytics currently do not factor risk/reward or balance one objective } \\
\text { against another }\end{array}$ \\
\hline $\begin{array}{l}\text { Stakeholder } \\
\text { Journey }\end{array}$ & $\begin{array}{l}\bullet \text { Analyse and measure attainment of customer value } \\
\bullet \text { Capture stakeholder sentiment via multiple channels including social } \\
\text { media }\end{array}$ \\
\hline Innovation & $\begin{array}{l}\bullet \text { Perpetuate Innovation } \\
\bullet \text { Quantitatively measure and encourage innovation }\end{array}$ \\
\hline $\begin{array}{l}\text { Employee } \\
\text { Empowerment }\end{array}$ & $\begin{array}{l}\bullet \text { Benefit realization not guaranteed by technology, change in behaviour } \\
\text { necessary }\end{array}$ \\
\hline
\end{tabular}

\section{REFERENCES}

[1] Sarfi, R.J. \& Gemoets, L., Making the Smart Grid work for Community Energy Delivery, Information Policy, 16(3), 277-291. DOI: 10.3233/IP-2011-0238.

[2] Wakefield, M., Guidebook for Cost/Benefit Analysis of Smart Grid Demonstration Projects, Electric Power Research Institute, May 2011.

[3] Elkington, J., Cannibals with Forks: The Triple Bottom Line of the $21^{\text {st }}$ Century, Capstone, 1997.

[4] Sarfi, R.J. \& Simmins, J., Balancing the Triple Bottomline: Building a Credible and Fundable Business Case, Distributech, San Diego, Jan. 2017.

[5] Cardenas, J.A., Gemoets, L., Ablanedo, J.H. \& Sarfi, R.J., A literature survey on Smart Grid distribution: an analytical approach, Journal of Cleaner Production, 65, pp. 202216,2014

[6] Sarfi, R.J., Don't be part of the problem: The asset is the data, EPRI GIS Focus Group, Birmingham, 2017.

[7] Nasr, N., Sustainable Manufacturing and Eco-Innovation: Framework, Practices, and Measurement, OECD, 2009.

[8] Tanaka, G.N. \& M., Gault, N., Oslo Manual: Guidelines for Collecting and Interpreting Innovation Data, OECD, 3rd ed., 2005. 